\title{
Environmental Inspection Proclivity and State Manufacturing Growth: The US Experience from the 1990s
}

\author{
by \\ Christopher S. Decker ${ }^{1}$ \\ Department of Economics \\ and Real Estate \\ College of Business Administration \\ University of Nebraska at Omaha \\ Omaha, NE 68182 \\ and \\ John W. Maxwell \\ Professor of Business Economics \& Public Policy \\ Kelley School of Business \\ Indiana University \\ Bloomington IN 47405
}

January 2010

\begin{abstract}
In this paper we construct a ranking of states based on their proclivity to inspect facilities for environmental compliance. Our measure utilizes state-level inspections data supplied by the US Environmental Protection Agency. After developing our ranking, we use it to predict state-level growth in manufacturing establishments. In doing so, we find support for the notion that enforcement intensity adversely impacts such growth. Our results offer insight into why existing studies that examine the impact of environmental regulation on location and growth produce inconsistent results.
\end{abstract}

Keywords: Monitoring and Enforcement, Environmental Regulations, Business Formation Growth

JEL Classifications: K32, Q28, R58

\footnotetext{
${ }^{1}$ Corresponding author: Christopher S. Decker, Department of Economics and Real Estate, College of Business Administration, University of Nebraska at Omaha, Omaha, NE 68182. Work number: 402 5542828. Email address: christopherdecker@mail.unomaha.edu.
} 


\title{
Environmental Inspection Proclivity and State Manufacturing Growth: The US Experience from the 1990s
}

\begin{abstract}
In this paper we construct a ranking of states based on their proclivity to inspect facilities for environmental compliance. Our measure utilizes state-level inspections data supplied by the US Environmental Protection Agency. After developing our ranking, we use it to predict state-level growth in manufacturing establishments. In doing so, we find support for the notion that enforcement intensity adversely impacts such growth. Our results offer insight into why existing studies that examine the impact of environmental regulation on location and growth produce inconsistent results.
\end{abstract}

Keywords: Monitoring and Enforcement, Environmental Regulations, Business Formation Growth

JEL Classifications: K32, Q28, R58 


\section{Introduction}

Does the enforcement of environmental regulations help or hinder the growth of a state's manufacturing base? There are two opposing responses to this question. Of these, the most traditional response is that environmental regulations, and their enforcement, tend to hinder growth. Compliance with regulations can be burdensome and costly, thus, when firms choose a manufacturing location they will opt for locales in which they expect to face less regulation and enforcement. The opposing view suggests that states with strict regulations and strict regulatory enforcement should see positive growth in their manufacturing base. This view is based on two arguments. First, in comparison with labor and manufacturing costs, environmental compliance costs are relatively small. Second, valued employees care about quality of life issues, of which the local environment is an important component. This view suggests that the benefits of locating in states with stricter environmental enforcement might outweigh the costs.

In this paper we attempt to directly test these two contrasting predictions using state-level data on regulatory enforcement and the growth in manufacturing establishments. ${ }^{2}$ An understanding of whether the level of environmental enforcement helps or hinders manufacturing growth is important to a number of constituencies. First, environmental economists are interested in answering this question because it can provide important insights into how corporations manage the costs and benefits of environmental compliance. Second, businesses, whether polluting or not, wish to know

\footnotetext{
${ }^{2}$ It is important to emphasize that we are focusing on the siting of new manufacturing establishments within states in our growth regression analysis as opposed to general manufacturing growth from the expansion of employment in both new as well as existing facilities. This is in deference to concerns that sufficiently strict environmental enforcement may cause plant closings and relocations to other states with more lax environmental enforcement (see, e.g., Gray, 1997). While this was the focus of the present study, a broader measure of growth would clearly be worth considering in subsequent research.
} 
whether legislative and regulatory activities help or harm an area's manufacturing base since, in many instances, manufacturing is a basic (export-oriented) industry integral to the overall sustainability and growth of a region's economy. Finally, state regulators and legislators need to know whether, and to what extent, their efforts help or harm manufacturing growth in order to optimize regulatory enforcement.

In addition to offering insights into these public policy questions, this study also addresses a gap in the literature on economic growth and environmental regulation that is important to environmental economists and policy makers alike. Barro (1991) developed a model of economic growth that suggested an econometric procedure that could be used to explain differences in economic growth among nations. Several authors have used Barro’s approach to attempt to explain differences in economic growth among states. A few papers have used measures of environmental quality and legislation, along with other economic variables, to explain economic growth (e.g., Goetz, Ready, and Stone, 1996; Polzin, 2001). Results have been mixed. These papers generally support the notion that environmental quality positively affects state economic growth, but there is less support for the notion that environmental regulation (enforcement) affects state economic growth.

These findings suggest that the literature has yet to adequately test the impact of an environmental (regulatory) regime. To see why, note that a strict environmental regime is most likely to affect manufacturers and is less likely to impact service industries. If all states' manufacturing sectors served as their economic base, that is as a basic (export-oriented) industry, then state-level measures of economic growth should reflect the impact of strict environmental regime. 
However, the extent to which manufacturing serves as a basic industry to a regional economy varies widely in the US. To see this, we'll employ a common empirical measure to identify basic industries, the location quotient (LQ). Using states as our regional economic delineation, the location quotient (LQ) is essentially a ratio of state shares of a variable (commonly employment) to the corresponding national share of that same variable. In general, if an industry's LQ is in excess of one, indicating that a state's employment share of a given industry is larger than the national share, then that industry is classified, in economic base theory, as a basic industry whereby much of the production of that industry is exported outside the state's economy. As such, the industry generates external revenues that support the growth and development of other (non-basic) industries in that state.

For example, employment data from the Bureau of Economic Analysis reveal a LQ for motor vehicle manufacturing in Michigan in 1995 of 7.17, strongly suggesting, as one might suspect, that auto manufacturing is clearly a basic industry and, as such, is a significant contributor to Michigan’s economic base. ${ }^{3}$ However, not all manufacturing industries are basic. In some economies, service industries are contributors to a state's economic basic. For instance, with an LQ of 1.6, the finance and insurance industry serves as an important contributor to the economic base of New York, while, with an LQ of 2.7, a major basic industry in Nevada is gambling and recreation. If the strictness of a state's environmental regime has differing impacts on economic growth depending on the makeup of a state's economic base then one should use, as a dependent variable, the growth rate of each state's manufacturing base.

\footnotetext{
${ }^{3}$ This data was obtained from http://www.bea.gov/regional/spi/. The year 1995 was chosen to reflect a reasonable LQ calculation for the period under consideration in this study.
} 
Further, previous studies have used the number of state-level environmental policies to measure the strictness of a state's environmental regime. This measure is questionable for several reasons. First, it is possible that a number of state regulatory policies, such as those dealing with landfill sites or those dealing with drinking water standards, have little or no impact on a broad range of manufacturers. Second, although federal regulations apply to all states, their impact on the manufacturing base depends on the degree to which they are enforced, which varies widely across states. Finally, policies can and do change over time. Since companies are likely to care less about regulatory policy changes and more about the degree and rigor with which policies are enforced, a measure of enforcement is desirable. Our methodology addresses these concerns by using a measure of environmental inspection proclivity, at the state level, based on three major federal environmental acts.

In constructing this measure, we adopt a procedure employed by List and McHone (2000). This procedure uses econometric techniques to purge from a raw measure of inspection intensity (based on inspection counts) systematic cross-sectional and time-varying effects. In the end we obtain a time-invariant measure of inspection proclivities (that is, a measure of the intrinsic importance of environmental protection) unique to each state. Based on this measure, we construct a state ranking of inspection proclivity. Adopting the nomenclature of List and McHone (2000), we refer to this as a “conditional ranking”, as opposed to an "unconditional ranking” based solely on the raw inspections data.

Controlling for cross-sectional variation is beneficial since certain industries located in only a few states may simply require more inspection activity given the nature 
of production. Some industries, for instance, are deemed "high priority" industries by the US EPA, demanding increased scrutiny. However, higher inspection activity due simply to industrial composition does not necessarily signal a greater proclivity to enforce regulations relative to other states with a different industrial composition. It simply may reflect, for instance, greater inspection activity required by federal authorities.

Likewise, controlling for time-varying patterns in inspection activity is useful in creating the conditional ranking. We know that industrial composition can change over time as plant closings and openings occur. If such changes happen in US EPA priority, or other high polluting industries, then inspection activity may fluctuate systematically over time. However, such changes in inspection rates do not necessarily reflect a change in a state's attitude toward environmental enforcement. For instance, a state may experience plant closings in a high-polluting industry but still may be inclined to aggressively inspect plants in other industries, particularly if that state is inherently disposed towards maintaining and improving environmental quality.

To our knowledge, only two other papers constructed state-level environmental indexes by following econometric procedures similar to the one we use here. Henderson (1994) for instance, attempts to construct a ranking of state "attitudes” towards air quality regulation by employing US Census data on capital expenditure and operating costs data for pollution abatement. ${ }^{4}$ However, as an indicator of enforcement proclivity this construction is indirect at best and possibly inaccurate since there may be other reasons for firms to invest in pollution abatement other than compliance (see, e.g. Lyon and

\footnotetext{
${ }^{4}$ This index was used in Henderson (1996) to test if such attitudes impact state ozone readings and did find that states with more progressive attitudes towards air quality realizes lower ozone readings, although this marginal effect is rather small. However, he did not test whether or not such attitudes impact business location decisions or establishment growth.
} 
Maxwell, 2004, and Segerson and Li, 2000 for detailed discussions of "voluntary" or "strategic" motivations for pollution abatement).

As noted above, List and McHone (2000) also construct a state ranking of environmental output by state. As a measure of air quality the ranking is very useful. However, our interest is in measuring a state's proclivity to enforce existing environmental regulations. Therefore, a different dataset is required. For instance, a state may have better air quality than others simply because the composition of the state's economy is dominated by low-polluting industries, having very little to do with the relative importance the state places on environmental enforcement. Fortunately, data on inspections do exist. We can use this data to construct a direct measure of enforcement proclivity. As we will see, our ranking based on inspections data generates different rankings than both Henderson (1994) and List and McHone (2000).

The paper is organized as follows. In section 2 we discuss the raw, or unconditional, inspections data and its characteristics. In sections 3 and 4 we discuss the need and procedure for developing a conditional ranking in more detail and the resulting econometric results. In section 5 we apply our conditional ranking to an analysis of determinants of manufacturing establishment growth. In section 6 we conclude.

\section{An Unconditional Ranking of Inspections}

The primary goal in this study is to ascertain, through as direct a measure as possible, a state's proclivity toward enforcement of environmental regulations. To this end we focus principally on inspection behavior. ${ }^{5}$ We obtained data on inspections

\footnotetext{
${ }^{5}$ Clearly, this is not the only measure of enforcement. One could focus attention on enforcement actions or penalties as a measure of enforcement intensity. Our contention is that inspections are a broader measure of enforcement. They indicate a state enforcement authorities' proclivity to enforce regulations on all potential violators.
} 
conducted by states for the Clean Air Act (CAA), the Clean Water Act (CWA), and the Resource Conservation and Recovery Act (RCRA) compliance between 1992 and 1998, from the US EPA's Office of Environmental Compliance and Assistance (OECA). ${ }^{6}$ To measure the intensity of inspection activity, we borrowed a concept from the economic geography and regional science literatures, and constructed a "location quotient" (LQ) for each state.

Specifically, we consider the calculation of a location quotient for state inspections per facility, LQIN, calculated as follows:

$$
L Q I N=\left(I_{\text {STATE }} / F A C_{\text {STATE }}\right) /\left(I N_{U S} / F A C_{U S}\right),
$$

where IN is the number of inspections and FAC is the number of facilities subject to inspections. ${ }^{7}$ Table 1 presents information ranking each state’s LQIN. According to the data, the top five states that are most inspection-intensive are Maryland, Alabama, Connecticut, Utah, and West Virginia. The least inspection-intensive states are New Mexico, New Hampshire, Rhode Island, Alaska, and Iowa.

In principal one could use this measure, or a ranking based on it, to explain differences in the growth of manufacturing facilities across states, but this is too simplistic. This measure does not control for potentially important systematic differences among states that may affect inspection intensity, but that have little to do with the true level of enforcement intensity a particular facility may expect to receive. For example, the LQIN measure does not take into account the industry mix of the manufacturing base. It may be the case that most facilities subject to inspection in, say, New Mexico are

\footnotetext{
${ }^{6}$ The data was made available to us in aggregate. That is, we do not have available CAA inspections separately from either CWA or RCRA inspections. Since our focus is on overall enforcement intensity the breakdown by statute is not of immediate interest.

${ }^{7}$ The inspections data are defined on a per facility basis because more inspections will occur where more polluting facilities exist.
} 
inherently less polluting than most facilities in, say, Alabama. This does not mean, however, that a given type of facility (such as an oil refinery) will be inspected less in New Mexico than in Alabama.

Several factors other than industry mix may have similar effects and must be controlled for in order to develop a proper estimate of environmental inspection proclivity. These factors include an industry's historical compliance record in a given state, and the relative importance of the polluting industry or industries to a state's economy. Regulators, as a matter of course, inspect more frequently facilities that have poor environmental records, or those known to produce high levels of pollution (see, e.g. Gray and Deily (1996), Dion, Lanoie, and Laplante (1998), and Decker (2005). At the same time, inspectors may shy away from inspecting facilities that are important to a state's economy. Again, however, these concerns will have little to do with the inspection intensity faced by a new facility that may not be crucial to the state's economic base.

Additionally, our conditional ranking of inspection proclivity should control for the influence of the general political attitudes of the population and the government of the state. The rationale for purging the influence of these variables from our measure of environmental inspection intensity is that while they are widely thought to influence regulatory behavior, political attitude may also influence other variables that also might help or hinder the growth of a state's manufacturing sector. For example, political attitudes might lead to stricter or weaker requirements for the granting of construction permits for new facilities or the expansion of existing facilities. Thus, in explaining the growth of a state's manufacturing sector, it may be beneficial to include these political attitude variables as separate regressors in order to avoid collinearity problems. 


\section{Construction of the Conditional Ranking}

In this section we develop a conditional ranking, based on LQIN, that has been purged of the systematic influences outlined in section 2. To this end, we assembled from a variety of sources a panel dataset that provides information on inspections and other variables across states over the period 1992 to 1998 . We then ran fixed effects (FE) and random effects (RE) regression models on this data.

The FE model is:

$$
y_{i, t}=\alpha_{i}+\beta X_{i, t}+\delta_{t}+\varepsilon_{i, t},
$$

where $y_{i, t}$ is each state $i$ 's LQIN for years $t=1992$ through 1998, $\alpha_{i}$ is the time-invariant estimated state constant variable, $\delta_{t}$ estimated time constant variable (for the years 1992 through 1998), $X_{i, t}$ is a 50 by 7 matrix of independent variables believed to influence LQIN, and $\varepsilon_{i, t}$ is a white noise error. Since our goal is to isolate a time-invariant state enforcement proclivity statistic, our resulting conditional ranking should be reflected in the estimated $\alpha_{i}$ 's. These coefficients, by construction, give us a time-invariant measure of inspection activity by state that is not explained by the independent variables defining $X_{i, t}$. Companies can see this behavior but standard statistical analysis can't reveal this attitude.

A FE is appropriate when one is confident that the cross-section and time series units can be viewed as parametric shifts in the regression. However, if the cross-section and time series constant terms are random variables distributed across cross-sectional and time series units, then the RE model, $y_{i, t}=\alpha+u_{i}+\beta X_{i, t}+\delta_{t}+\varepsilon_{i, t}$, is appropriate. As we detail in Section 4, the Hausman test for FE versus RE strongly favors the FE model. 
More complete definitions and explicit construction of the independent variables used in our regression analysis are described in greater detail in this paper's appendix (Table A1). Our fixed effects model is:

$$
\begin{aligned}
& L Q I N_{i, t}=\alpha_{i}+\delta_{t}+\beta_{1} L Q E N A V G_{i, t}+\beta_{2} L Q T R I_{i, t-2} \\
& +\beta_{3} L Q E L E C_{i, t}+\beta_{4} L_{Q C I T}+\beta_{i, t} L Q G O V_{i, t}+\beta_{6} L_{Q D E N S I T Y}{ }_{i, t} \\
& +\beta_{7} L Q G S P_{i, t}+\sum_{\substack{j=26,28,29, 30,33}} \beta_{j} L Q G S P j_{i, t}+\sum_{\substack{k=26,28,29, 30,33}} \beta_{k} L Q T R I k_{i, t-2}+\varepsilon_{i t} .
\end{aligned}
$$

The independent variables enter equation (2) as location quotients to ensure consistency in the error term. ${ }^{8}$ The variable LQENAVG measures the average number of per facility enforcement actions levied over the four years prior to current inspections by states for CAA, CWA and RCRA violations (relative to the number of actions per facility levied at the US level). As with the inspection data, the enforcement data was provided by OECA. We expect higher relative prior enforcement actions to subsequently prompt more frequent inspections (see, e.g. Harrington, 1988).

In addition, as many studies have shown, higher per capita pollutant releases are likely to prompt greater state-level inspection activity. Our measure of pollution releases comes from the EPA's Toxic Release Inventory (TRI) database. ${ }^{9}$ Using this data, we constructed LQTRI, which measures per capital TRI releases for EPA designated core chemicals by state relative to per capita TRI releases. The reason we use the two-year lag of LQTRI as an explanatory variable is that the TRI data tends to be released to the

\footnotetext{
${ }^{8}$ To be sure, there are a number of possible specifications for equation (2) and we tried a number of them. The one we decided upon here offered the most reasonable results in terms of goodness of fit.

${ }^{9}$ The TRI data can be obtained quite easily at http://www.epa.gov/triexplorer/. The population data was obtained by the US Department of Commerce's Regional Economic Information Service (REIS). The REIS data can be queried at http://www.bea.doc.gov/bea/regional/reis/.
} 
general public with about an eighteen month lag. We would expect to see a positive coefficient result.

It is also reasonable to presume that certain industries might experience more inspections given the amount and nature of the pollutant releases involved. Indeed, the EPA has designated several industries as "high priority" industries requiring increased scrutiny. ${ }^{10}$ The five industries relevant here are pulp and paper (SIC 26), chemical manufacturing (SIC 28), petroleum refining (SIC 29), rubber and plastics (SIC 30), and iron and steel (SIC 33). To incorporate this effect, we constructed variables (LQTRI26, LQTRI28, LQTRI29, LQTRI30, and LQTRI33) to measure, for each state, an industry’s TRI releases per dollar's worth of GSP in that same industry relative to each state's overall TRI releases per dollar's worth of state manufacturing GSP. ${ }^{11}$ We would expect higher inspection intensity in those states whose TRI releases are proportionately larger in these sectors. Therefore, positive coefficients on these variables are anticipated.

In addition to pollutant releases, inspectors may consider the level of production as an additional indication of a firm's potential to violate environmental law. As a measure of aggregate production, we utilize the US Department of Commerce's real gross state product (GSP) data. We construct LQGSP to measure overall real gross state product per capita relative to US real gross national product per capita.

Moreover, for reasons stated earlier, we also consider production levels (as measured by industry-level GSP) for the five priority industries identified above as well.

\footnotetext{
${ }^{10}$ The US EPA's Office of Compliance and Enforcement publishes this list annually in its Enforcement and Compliance Accomplishments reports. See http://www.epa.gov/Compliance/resources/reports/planning/results/fy98accomplishment.pdf for details.

${ }^{11}$ Industry level gross state production (GSP) data is available from the US Department of Commerce at http://www.bea.doc.gov/bea/regional/gsp.htm. The reason we focus on industry releases relative to total manufacturing GSP is because during the 1990s the TRI data was collected only for these industries classified as manufacturing sectors.
} 
Each of these LQs measure the share of each industry's GSP to total manufacturing GSP for each state divided by the same share for the nation as a whole.

The prior expectation of each of these variables' marginal effect on LQIN is unclear. While we might expect that greater industrial production generates the potential for greater environmental harm thereby prompting more inspections, it is possible that some of these sectors represent a relatively powerful economic interest within a particular state. To the extent that such industries may have been able to "capture" environmental enforcement officials, it might be the case that the resulting effects of all or some subset of these GSP LQs could have a negative impact on LQIN. Hence, a clear prior expectation is not easily identified.

Other control variables include population density (LQDENSITY), general political attitudes of the population (LQCIT and LQELEC) and elected officials (LQGOV). With respect to population density, we would expect to see greater inspection intensity the greater the concentration of citizens at risk of environmental harm. Political attitudes of a state's citizenry are measured by LQCIT and LQELEC. LQCIT comes from Berry, Ringquest, Fording, and Hanson (1998) and measures the ratio of a state's “citizen political ideology" score to the US average over the period 1990 to 1998. Citizen political ideology is generally thought of as a state's mean position on a liberalconservative continuum primarily based on voting behavior in local, US congressional, and presidential elections. This index is constructed in such a way that the higher the index, the more "liberal" the state (see Berry et al. for details). These indexes don't necessarily give an indication of how politically active state' population is. To measure how politically active state citizens are, we include LQELEC. Because in general US 
citizens are more active in presidential elections, LQELEC measures the percent of the voting population by state for the presidential elections 1988, 1992 and 1996. We expect each to have a positive effect on LQIN.

LQGOV, again based on Berry, et al. (1998), is the ratio of a state's “elected public official political ideology" score to the US average. Elected officials’ political ideologies can be thought of generally as a state's mean position on a liberal-conservative continuum. But here the scores are based on publicly available voting behavior of these elected officials on a number of issues classified as "liberal” vs. "conservative." This index is constructed in such a way that the higher the index, the more "liberal" the state (see Berry et al. (1998) for details). Table 2 presents summary statistics of the variables used in equation (2) as well as the variables used in our subsequent business formation growth regressions. $^{12}$

\section{Panel Estimation Results}

The FE and RE results are presented in Table 3. In order to test which model is better suited to the data we ran a Hausman test. We found the Hausman statistic to be 45.96 which, with 17 degrees of freedom, strongly favors the FE model. Moreover, we are explaining about 79 percent of the variation in LQIN and the F-statistic from our model suggests that we can safely reject the null hypothesis that our estimated coefficients on all of our independent variables are jointly equal to zero.

\footnotetext{
${ }^{12}$ Ideally, other important variables would be included in our model, such as number of inspectors employed, or perhaps a measure of state-level environmental budgets. However, we were unable to locate inspector employment data by state. We were, however, able to obtain some data for state-level environmental budgets for the sub-period 1994 to 1998 from the Environmental Council of the States. While this did limit the size of our dataset, we did introduce this variable in several ways (as a share of total state budgets, on a per-capita basis, and as an LQ where state environmental budgets per capita were divided by total state budgets per capita). In each instance the variable proved statistically insignificant and generated poorer overall statistical results. As such we have chosen to present the results without this data. To be sure, there is still merit in pursuing such data extensions. By way of future research, it may be beneficial to survey state environmental agencies to determine the number of inspectors employed.
} 
In the interest of brevity, we will highlight only a few key results from the FE model. First, as evidenced by the significance of LQENAVG, we find that historical noncompliance does statistically impact subsequent inspection intensity. Moreover, the results indicate that in more densely populated states inspection activity is more intensive.

We also find that inspection intensity tends to be greater in states with more politically active residents (as indicated by the significance of the LQELEC and LQCIT variables). As far as specific sectors are concerned, we find that higher relative emissions in pulp and paper plants tend to lead to significant increases in relative inspection activity. Interestingly, results indicate that chemical plants are inspected relatively less intensively, ceteris paribus, which may be indicating the possibility of industrial capture in this sector or the possibility of industry self-regulation measures. ${ }^{13}$

In terms of the relationship between pollution releases and inspection intensity, there is some evidence that higher TRI releases per GSP prompt more intensive inspection activity in the pulp and paper and chemical manufacturing sectors, ceteris paribus. However, contrary to expectation, we find the higher TRI releases per GSP in the oil refining sector prompt less subsequent inspection intensity. ${ }^{14}$

In terms of the resulting conditional state ranking obtained from the FE model presented in Table 4, we find some significant differences when compared to the unconditional ranking. We find that the four states with the highest inspection proclivity

\footnotetext{
${ }^{13}$ See Lyon and Maxwell (2004) for a detailed study of corporate motivations for self-regulation, including the American Chemistry Council's (formally, the Chemical Manufacturing Association) creation of the self-regulatory Responsible Care program.

${ }^{14}$ This counter-intuitive result is certainly troubling and, while it is the case that relative to the other sectors TRI releases in this sector are relatively small, this result may suggest that for this sector, a more refined measure of pollution may be necessary.
} 
are Wyoming, Utah, West Virginia, and Alabama, while the four with the least proclivity are New Jersey, Rhode Island, Massachusetts, and Connecticut.

It is worth pointing out some similarities and differences with existing state environmental rankings. For instance, List and McHone's (2000) rankings of states based on air pollution places Wyoming eleventh, a relatively high ranking. That is, Wyoming will tend to have relatively few ozone monitors indicating exceedance of federal air quality regulations. To be sure, there are some striking differences as well. In contrast to our finding that New Jersey has the lowest inspection proclivity, List and McHone (2000) find that New Jersey tended to have the smallest percentage of ozone monitors indicating larger than allowable pollutant releases.

\section{State Environmental Regulatory Attitudes and New Business Formation}

The growth model. One application of the state ranking is to test whether or not a state's inspection proclivity impacts the economic landscape of a state. There are a number of studies that have investigated the relationship between plant location, production decisions and environmental regulation. ${ }^{15}$ Using state-level data on new manufacturing plant construction, Gray (1997) for instance, found that fewer new plants were built in those states where environmental enforcement was more aggressive. Other studies suggest alternative conclusions. Goetz, Ready, and Stone (1996), for instance, investigated the impact various measures of state environmental quality have on the growth in state per capita income. Their state environmental policy index (which incorporates 17 policy areas including a number of enforcement policies such as hazardous waste management and groundwater protection plans) was found to have no statistical impact on per capita income growth.

${ }^{15}$ See, for instance, Jeppesen, List, and Folmer (2002), List and Co (2000), and Gray (1997). 
While both studies have substantial merit, there are a number of aspects that, in light of our results so far, deserve some re-consideration. First, Gray's (1997) results treated enforcement, measured as number of inspections, as exogenous and independent of his other model variables, including industry output. However, our results suggest that inspections are indeed endogenous, influenced by, among other variables, industry output. Hence, Gray’s (1997) results linking enforcement with plant location may be premature and further investigation is in order. With respect to Goetz, Ready, and Stone (1996), their results are based on an environmental index measure that embodied a variety of policy variables, not simply enforcement and thus any deference to the enforcement effect on growth was at best indirect.

In this section we apply an economic growth model similar to Goetz, Ready, and Stone, which is largely an adaptation of Barro's (1991) growth study. Rather than focus on employment or income growth directly, more consistent with Gray's analysis, we use new establishment data for the period 1990 to 2000 from the Small Business Administration (SBA). We look at overall growth between 1990 and 2000 for manufacturing establishments and test the impact of our conditional (and unconditional) index on this growth. We then look at growth patterns between 1990 and 2000 for small establishments (generally defined by the SBA as having fewer than 500 employees) and large establishments (500 or more employees).

The empirical model specified is

$$
\begin{aligned}
& \ln (\text { MAN2000 })-\ln (\text { MAN1990 })=\alpha+\beta_{1} \text { MAN1990 }+\beta_{2} \text { PRODUCTIVITYGR }+ \\
& \beta_{3} \text { EDUC }+\beta_{4} \text { TAXIND }+\beta_{5} \text { INSRANK }(C O N D)+\beta_{6} \text { GREENINDEX }+e .
\end{aligned}
$$

MAN1990 and MAN2000 measure the number of manufacturing establishments counted by state in 1990 and 2000, respectively. PRODUCTIVITYGR measures the growth in 
GSP per worker between 1990 and 2000. One would expect this variable to positively impact growth. EDUC measures the percent of a state's population with a high school degree or higher. We would expect this variable to have a positive effect on new establishment growth. TAXIND is an index constructed by the Tax Foundation measuring the business tax climate by state. ${ }^{16}$ The higher the index, the more favorable the tax structure is to business. We would expect this variable to have a positive effect on growth. GREENINDEX is the same environmental policy index used by Goetz, Ready, and Stone (2000). INSRANK is simply the ranking based on INLQ from Table 1, and INSRANKCOND is the INLQ conditioned on the explanatory variables and what are represented in Table 4.

Econometric Results. In Table 5 we present the results of the above specification when using INSRANK and INSRANKCOND, respectively. In Table 6 we present the results of two estimations using only INSRANKCOND in both. The first looks at growth of large establishments where MANLG1990 and MANLG2000 measure the number of manufacturing establishments counted by state that employ 500 or more workers in 1990 and 2000, respectively. The second looks at growth of smaller establishments where MANSM1990 and MANSM2000 measure the number of manufacturing establishments counted that employ less than 500 workers.

Based on the adjusted $\mathrm{R}^{2}$ and F-statistics, we see that the growth specification employing INSRANKCOND offers a better explanation of manufacturing establishment growth. There is little evidence of growth convergence across states as evidenced by the positive and insignificant sign on MAN1990. The educational attainment of a state's population proves insignificant (a result consistent with a variety of studies such at

\footnotetext{
${ }^{16}$ This data was obtained from http://www.facilitycity/busfac/bf_03_06_exclusive1.asp, November, 2003.
} 
Polzin, 2001). Moreover, TAXIND and GREENINDEX are not significant indicators of establishment growth.

There is some evidence to support the notion that firms are attracted to build new plants in states with more productive workforces and in states with lower poverty rates. ${ }^{17}$ Importantly, as indicated by the negative and significant impact of INSRANKCOND, we do see that manufacturing establishment growth is slowed in states with more intensive environmental inspection activity, ceteris paribus. While this impact conforms to prior expectation, it is worthwhile to point out that had just the unconditional ranking been employed, we would not have concluded that any impact exits. Nonetheless, once our conditional measure of inspection intensity is constructed, we do find a negative impact on business growth.

It is also interesting to note that, as we see in Table 6, INSRANKCOND's impact on establishment growth is consistent across size of production facilities. Growth in establishments generating 500 or more jobs is slower in states with a higher inspection proclivity ranking to nearly the same degree as growth in smaller establishments (employing less than 500 people) is retarded. That said, the results do point out some other differences in determinants of manufacturing establishment growth. For instance, smaller facilities tend to be attracted to states with higher productivity levels and lower poverty rates. However, firms tend to build larger facilities in states with a more favorable business tax climate.

\footnotetext{
${ }^{17}$ The statistical significance of PRODUCTIVITYGR and the insignificance of EDUC may be picking up certain unobservable characteristics of the manufacturing establishment data. It may be that most of the establishments constructed are primarily the production and distribution of goods for which an established market exists. Were it possible to distinguish between production and distribution facilities and, say new product development and R\&D facilities, EDUC may be a significant determinant of the latter and not of the former.
} 


\section{Conclusion}

When utilizing a more direct measure of enforcement to construct a conditional ranking of a state's proclivity towards environmental regulations, we find results that differ from existing rankings that measure such effects indirectly. When applied to the question of whether or not enforcement of existing regulations influences the growth of business establishment formation, we find that our conditional ranking of inspection proclivity does indeed have a significant deterring effect on such growth. Thus, our results generally support the notion that enforcement of environmental regulation hinders a state’s manufacturing growth prospects.

There are several directions for future research. First, it may be of interest to conduct a similar analysis of the European Union and compare enforcement proclivity’s impact on manufacturing growth with that of the United States. Second, it would be of interest to re-consider this analysis in a contemporary setting. For instance, states with a greater proclivity towards aggressive enforcement likely prompt improved compliance and better environmental stewardship on the part of its existing manufacturing base. If a cap-and-trade policy is adopted, these manufacturing firms may find themselves with a competitive advantage in carbon trading which many provide opportunities. We leave these questions for future research. 


\section{References}

Barro, R. 1991. "Economic Growth in a Cross-Section of Countries," Quarterly Journal of Economics, 106(2), 407-43.

Berry, W. D., Ringquist, E. J., Fording, R. C., and Hanson, R. L. 1998. "Measuring Citizen and Government Ideology in the American States, 1960-93.” American Journal of Political Science, 42(1), 327-48.

Decker, C. S. 2005. Do Regulators Respond to Voluntary Pollution Control Efforts? A Count Data Analysis.” Contemporary Economic Policy, 23(2), 180-194.

Dion, C., Lanoie, P., and Laplante, B. 1998. "Monitoring of Pollution Regulation: Do Local conditions Matter?” Journal of Regulatory Economics, 13(1), 5-18.

Goetz, S. J. Ready, R. C., and Stone, B. 1996. "US Economic Growth vs. Environmental Conditions.” Growth and Change, 27, 97-110.

Gray. W. B. 1997. "Manufacturing Plant Location: Does State Pollution Regulation Matter?” NBER working paper no. 5880. National Bureau of Economic Research, Inc.

Gray, W. B. and Deily, M. 1996. "Compliance and Enforcement: Air Pollution Regulation in the US Steel Industry.” Journal of Environmental Economics and Management, 31(1), 96-111.

Harrington, W. 1988. “Enforcement Leverage When Penalties are Restricted.” Journal of Public Economics, 37, 29-53.

Henderson. J. V. 1994. State Attitudes Towards Air Quality Regulation. Working paper, Brown University, March. 1994.

Henderson. J. V. 1996. “Effects of Air Quality Regulation.” American Economic Review, 86(4), 789-813.

Jeppesen, T., List, J. A., and Folmer, H. 2002. "Environmental Regulations and New Plant Location decisions: Evidence from a Mata-analysis.” Journal of Regional Science, 42(1), 19-49.

List, J. A., and Co, C. Y. 2000. "The Effects of Environmental regulation on Foreign Direct Investment.” Journal of Environmental Economics and Management, 40(1), 1-20.

List, J. A. and McHone, W. 2000. "Ranking State Environmental Outputs: Evidence from Panel Data.” Growth and Change, 31, 23-39. 
Lyon, T. P., and Maxwell, J. W. 2004. Corporate Environmentalism and Public Policy, Cambridge University Press, Cambridge, U.K.

Polzin. P. E. 2001. "Why Some States Grow Faster than Others: New Growth Models for State Economic Policy.” Growth and Change, 32, 413-425.

Segerson, K., and Li, N. 2000. Voluntary Approaches to Environmental Regulation, in The International Yearbook of Environmental and Resource Economics ( Hank Folmer and Tom Tietenberg, Eds.), Kluwer. 
Table 1. Unconditional State Rankings fore LQIN

\begin{tabular}{|c|c|c|}
\hline STATE & Mean (unconditional) & Rank (unconditional) \\
\hline AK & 0.4475 & 47 \\
\hline AL & 2.1967 & 2 \\
\hline AR & 1.2579 & 12 \\
\hline AZ & 0.5923 & 42 \\
\hline CA & 0.8786 & 26 \\
\hline $\mathrm{CO}$ & 0.8637 & 28 \\
\hline $\mathrm{CT}$ & 0.6084 & 39 \\
\hline $\mathrm{DE}$ & 1.8591 & 3 \\
\hline FL & 0.9359 & 23 \\
\hline GA & 0.8442 & 29 \\
\hline HI & 1.1943 & 14 \\
\hline IA & 0.4850 & 46 \\
\hline ID & 0.7201 & 36 \\
\hline IL & 0.9637 & 22 \\
\hline IN & 1.1523 & 15 \\
\hline KS & 1.0612 & 16 \\
\hline KY & 1.4104 & 8 \\
\hline LA & 1.2433 & 13 \\
\hline MA & 0.5270 & 44 \\
\hline MD & 2.3152 & 1 \\
\hline ME & 0.7948 & 31 \\
\hline MI & 0.7356 & 34 \\
\hline MN & 0.5483 & 43 \\
\hline MO & 0.7414 & 33 \\
\hline MS & 1.2746 & 11 \\
\hline MT & 0.9891 & 20 \\
\hline NC & 1.3154 & 10 \\
\hline ND & 0.9114 & 24 \\
\hline $\mathrm{NE}$ & 0.9051 & 25 \\
\hline $\mathrm{NH}$ & 0.4327 & 49 \\
\hline NJ & 0.8766 & 27 \\
\hline NM & 0.3640 & 50 \\
\hline NV & 0.6003 & 40 \\
\hline NY & 0.5060 & 45 \\
\hline $\mathrm{OH}$ & 0.7051 & 37 \\
\hline OK & 0.7791 & 32 \\
\hline OR & 0.9811 & 21 \\
\hline PA & 1.5049 & 6 \\
\hline RI & 0.4378 & 48 \\
\hline SC & 1.3211 & 9 \\
\hline SD & 0.5979 & 41 \\
\hline $\mathrm{TN}$ & 1.0445 & 18 \\
\hline TX & 0.9898 & 19 \\
\hline UT & 1.6624 & 4 \\
\hline VA & 1.4746 & 7 \\
\hline VT & 0.8239 & 30 \\
\hline WA & 0.7210 & 35 \\
\hline WI & 0.6213 & 38 \\
\hline WV & 1.6180 & 5 \\
\hline WY & 1.0524 & 17 \\
\hline
\end{tabular}


Table 2. Summary Statistics

\begin{tabular}{|c|c|c|c|}
\hline Variable & Mean & $\begin{array}{r}\text { Standard } \\
\text { Deviation }\end{array}$ & Observations \\
\hline \multicolumn{4}{|c|}{ A. Variables used in inspections equation } \\
\hline LQIN & 0.978 & 0.501 & 450 \\
\hline LQENAVG & 0.992 & 0.429 & 446 \\
\hline LQTRI & 1.282 & 1.558 & 450 \\
\hline LQELEC & 1.049 & 0.145 & 450 \\
\hline LQCIT & 1.000 & 0.284 & 450 \\
\hline LQGOV & 1.034 & 0.567 & 450 \\
\hline LQDENSIT & 2.178 & 2.902 & 450 \\
\hline LQGSP & 0.966 & 0.168 & 450 \\
\hline LQGSP26 & 1.099 & 1.031 & 450 \\
\hline LQGSP28 & 0.957 & 0.945 & 450 \\
\hline LQGSP29 & 1.406 & 2.269 & 450 \\
\hline LQGSP30 & 0.947 & 0.474 & 450 \\
\hline LQGSP33 & 0.940 & 0.810 & 450 \\
\hline LQTRI26 & 0.972 & 1.169 & 450 \\
\hline LQTRI28 & 1.152 & 2.902 & 450 \\
\hline LQTRI29 & 1.123 & 1.770 & 450 \\
\hline LQTRI30 & 1.070 & 0.977 & 450 \\
\hline LQTRI33 & 0.789 & 1.748 & 450 \\
\hline \multicolumn{4}{|c|}{ B. Variables used in establishment growth equations } \\
\hline MAN2000 & $14,145.020$ & $15,942.670$ & 50 \\
\hline MAN1990 & $13,577.140$ & $16,130.930$ & 50 \\
\hline MANLG2000 & $4,186.840$ & $4,414.917$ & 50 \\
\hline MANLG1990 & $2,559.120$ & $2,864.032$ & 50 \\
\hline MANSM2000 & $9,958.180$ & $11,696.210$ & 50 \\
\hline MANSM1990 & $11,018.020$ & $13,337.120$ & 50 \\
\hline PRODUCTIVITYGR & 1.161 & 0.115 & 50 \\
\hline EDUC & 0.197 & 0.025 & 50 \\
\hline & 5.996 & 1.096 & 50 \\
\hline \multicolumn{4}{|l|}{ GREENINDEX } \\
\hline INSRANK & 25.500 & 14.577 & 50 \\
\hline INSRANKCOND & 25.500 & 14.577 & 50 \\
\hline
\end{tabular}


Table 3. Panal Regression Results (Fixed and Random Effects Models)

Dep. Var.: LQIN

\begin{tabular}{|c|c|c|c|c|c|c|}
\hline \multirow[b]{2}{*}{ Variable } & \multicolumn{3}{|c|}{ Fixed Effects (FE) } & \multicolumn{3}{|c|}{ Random Effects (RE) } \\
\hline & Coefficient & p-value & & Coefficient & p-value & \\
\hline Constant & -1.3621 & 0.1230 & & 0.6444 & 0.1502 & \\
\hline LQENAVG & 0.0003 & 0.0315 & $* *$ & 0.0003 & 0.0276 & $* *$ \\
\hline LQTR[-2] & 0.0130 & 0.7396 & & 0.0326 & 0.2419 & \\
\hline LQELEC & 0.5784 & 0.0540 & $*$ & -0.1280 & 0.5918 & \\
\hline LQCIT & 0.2639 & 0.0808 & $*$ & 0.0269 & 0.8306 & \\
\hline LQGOV & -0.0559 & 0.3127 & & 0.0063 & 0.8883 & \\
\hline LQDENSIT & 0.6083 & 0.0044 & $* * *$ & -0.0048 & 0.8255 & \\
\hline LQGSP & 0.1826 & 0.7155 & & 0.0921 & 0.7505 & \\
\hline LQGSP26 & 0.2104 & 0.0014 & $* * *$ & 0.1429 & 0.0010 & $* * *$ \\
\hline LQGSP28 & -0.1248 & 0.0962 & $*$ & 0.0818 & 0.0753 & $*$ \\
\hline LQGSP29 & -0.0015 & 0.9534 & & 0.0053 & 0.7403 & \\
\hline LQGSP30 & -0.1589 & 0.1527 & & -0.0375 & 0.6586 & \\
\hline LQGSP33 & 0.0619 & 0.3673 & & 0.1317 & 0.0096 & $* * *$ \\
\hline LQTRI26[-2] & 0.0346 & 0.0835 & $*$ & 0.0290 & 0.1233 & \\
\hline LQTRI28[-2] & 0.0134 & 0.0658 & $*$ & 0.0049 & 0.4718 & \\
\hline LQTRI29[-2] & -0.0562 & 0.0009 & $* * *$ & -0.0388 & 0.0113 & $* *$ \\
\hline LQTRI30[-2] & 0.0257 & 0.4120 & & 0.0020 & 0.9430 & \\
\hline LQTRI33[-2] & -0.0255 & 0.2224 & & -0.0091 & 0.6101 & \\
\hline Adj. $\mathrm{R}^{2}$ & 0.79 & & & 0.35 & & \\
\hline F Statistic $(75,374)$ & 18.88 & 0.000000 & $* * *$ & & & \\
\hline LM Statistic (2 d.f. $)^{1}$ & 567.80 & 0.000000 & $* * *$ & & & \\
\hline Hausman Statistic (17 d.f. $)^{2}$ & 45.96 & 0.000175 & $* * *$ & & & \\
\hline
\end{tabular}

* - Significant at the $10 \%$ level.

** - Significant at the 5\% level.

$* * *$ - Significant at the $1 \%$ level.

${ }^{1}$ Higher values of the LM statistic favor the FE or RE models over the

${ }^{2}$ Higher values of the Hausman statistic favor the FE model over the RE model. 
Table 4. Conditional State Rankings fore LQIN

\begin{tabular}{|c|c|c|}
\hline STATE & FE state coeff. & Rank (conditional) \\
\hline $\mathrm{AK}$ & 0.80971 & 20 \\
\hline AL & 1.67505 & 4 \\
\hline AR & 0.94569 & 15 \\
\hline $\mathrm{AZ}$ & 0.73872 & 21 \\
\hline CA & -0.3252 & 39 \\
\hline $\mathrm{CO}$ & 1.00866 & 14 \\
\hline $\mathrm{CT}$ & -4.42904 & 47 \\
\hline $\mathrm{DE}$ & 0.14131 & 33 \\
\hline FL & -0.71567 & 43 \\
\hline GA & 0.23019 & 31 \\
\hline HI & -0.18953 & 37 \\
\hline IA & 0.49044 & 27 \\
\hline ID & 0.85098 & 17 \\
\hline IL & -0.12037 & 35 \\
\hline IN & 0.32843 & 29 \\
\hline $\mathrm{KS}$ & 1.24369 & 8 \\
\hline KY & 1.025 & 13 \\
\hline LA & 1.10689 & 10 \\
\hline MA & -5.0362 & 48 \\
\hline MD & -0.83883 & 44 \\
\hline $\mathrm{ME}$ & -0.58723 & 42 \\
\hline MI & 0.21585 & 32 \\
\hline $\mathrm{MN}$ & -0.15012 & 36 \\
\hline MO & 0.63607 & 24 \\
\hline MS & 1.27902 & 7 \\
\hline MT & 0.84638 & 18 \\
\hline $\mathrm{NC}$ & 1.06685 & 12 \\
\hline ND & 1.10178 & 11 \\
\hline $\mathrm{NE}$ & 1.28257 & 6 \\
\hline $\mathrm{NH}$ & -0.54478 & 41 \\
\hline NJ & -6.97248 & 50 \\
\hline NM & 0.59415 & 25 \\
\hline NV & 1.19681 & 9 \\
\hline NY & -2.0142 & 46 \\
\hline $\mathrm{OH}$ & -1.19808 & 45 \\
\hline OK & 1.55065 & 5 \\
\hline OR & 0.66402 & 23 \\
\hline PA & -0.37936 & 40 \\
\hline RI & -6.35578 & 49 \\
\hline SC & 0.93568 & 16 \\
\hline SD & 0.72772 & 22 \\
\hline TN & 0.40785 & 28 \\
\hline TX & 0.83063 & 19 \\
\hline UT & 1.7166 & 2 \\
\hline VA & 0.58366 & 26 \\
\hline VT & 0.24007 & 30 \\
\hline WA & 0.07598 & 34 \\
\hline WI & -0.19915 & 38 \\
\hline WV & 1.70364 & 3 \\
\hline WY & 1.80528 & 1 \\
\hline
\end{tabular}


Table 5. Growth in Manufacturing Establishments, 1990-2000

Dep. Var.: Ln(MAN2000)-Ln(MAN1990)

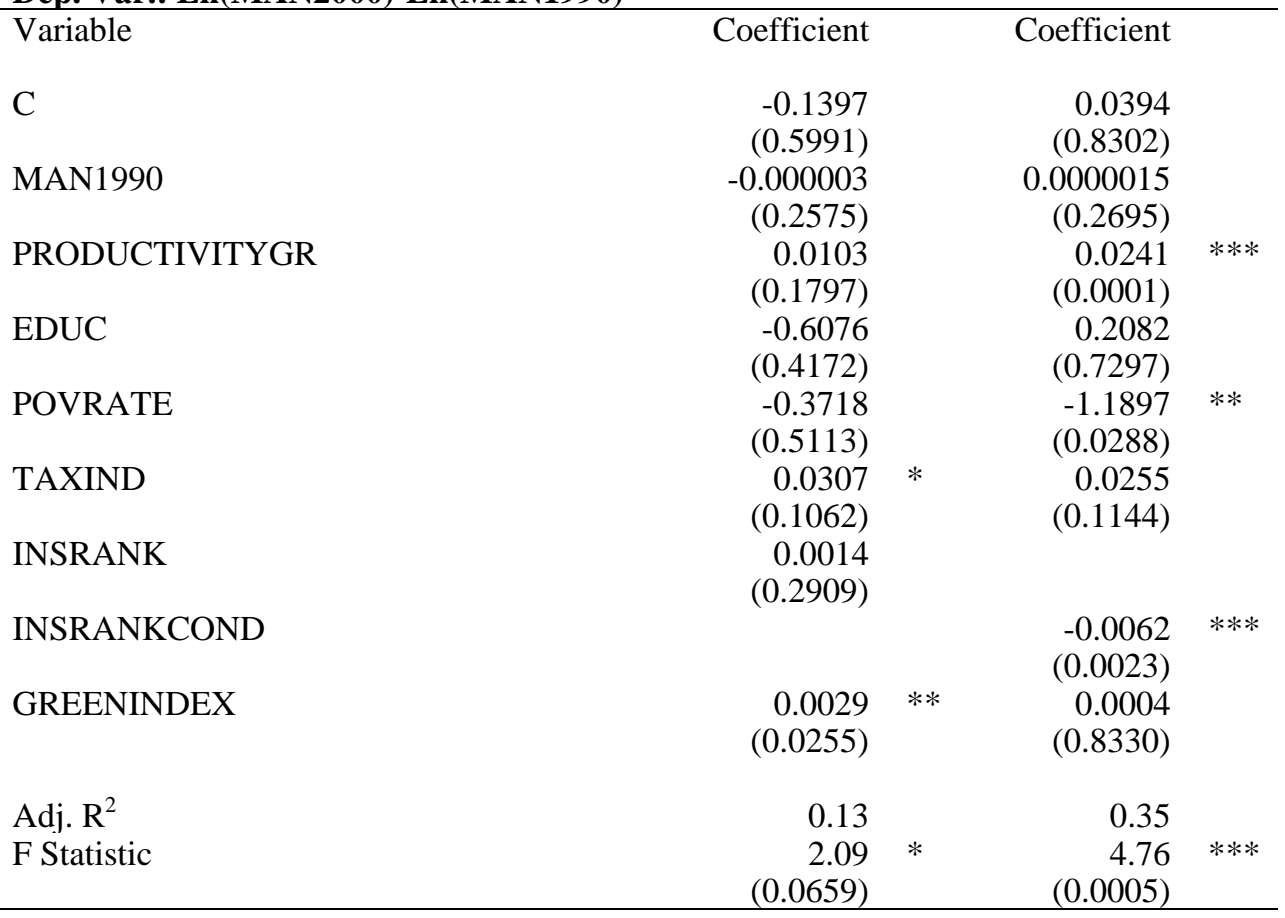

Note: White Heteroskedasticity-Consistent Standard Errors \& Covariance.

p-values in parentheses.

* - Significant at the $10 \%$ level.

** - Significant at the $5 \%$ level.

$* * *$ - Significant at the $1 \%$ level. 
Table 6. Growth in Manufacturing Establishments by Size, 1990-2000 Dep. Var.: Ln(MANx2000)-Ln(MANx1990) ${ }^{1}$

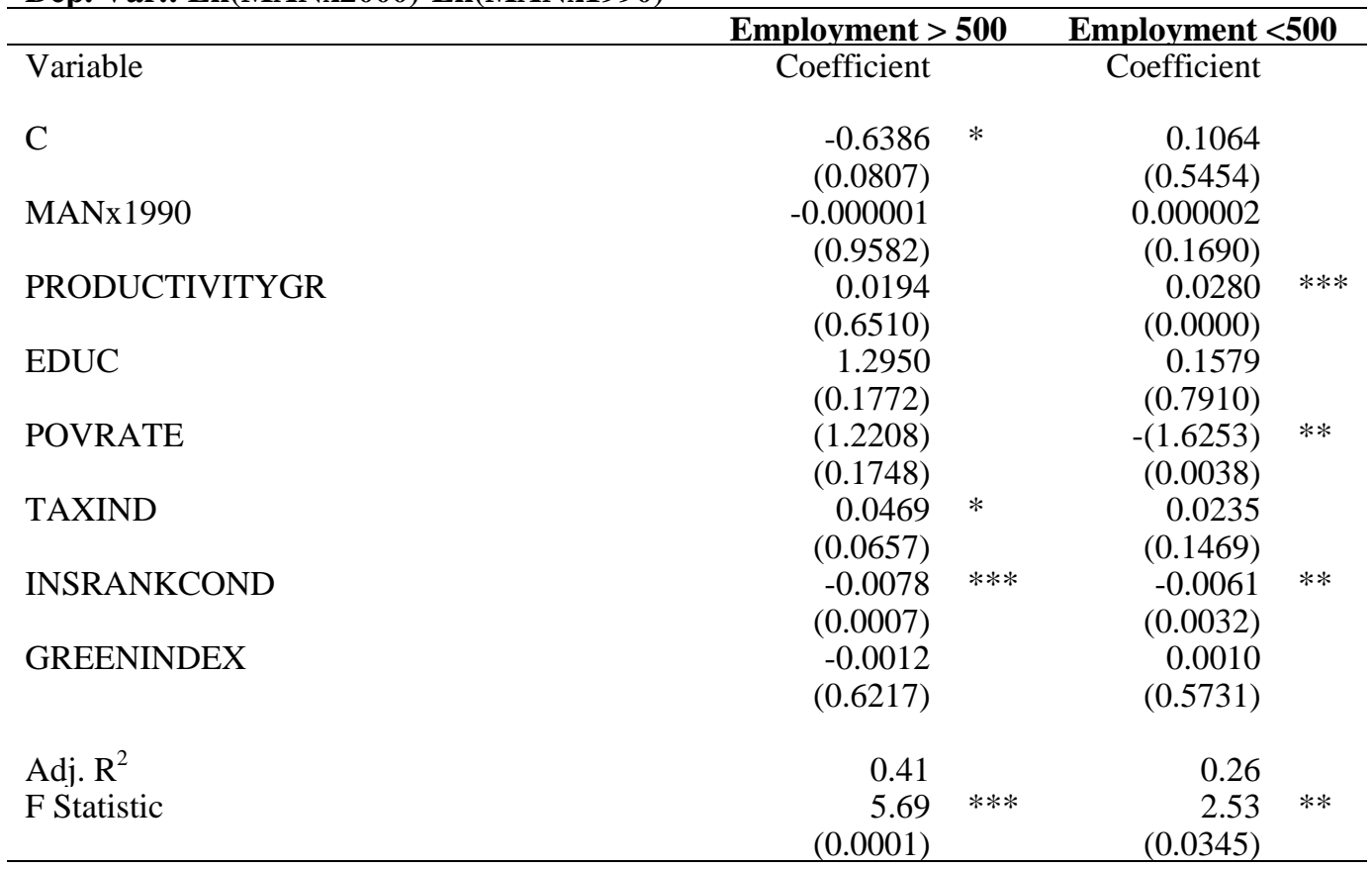

${ }^{1} \mathrm{x}=\mathrm{LG}, \mathrm{SM}$.

Note: White Heteroskedasticity-Consistent Standard Errors \& Covariance. $\mathrm{p}$-values in parentheses.

* - Significant at the $10 \%$ level.

** - Significant at the $5 \%$ level.

$* * *$ - Significant at the $1 \%$ level. 
Appendix Table A1. Variable Construction

\begin{tabular}{|c|c|c|}
\hline Variable & Definitions & LQ Construction \\
\hline LQIN & Inspections & $L Q I N=\frac{I N_{\text {STATE }} / F A C_{\text {STATE }}}{I N_{U S} / F A C_{U S}}$ \\
\hline LQEN & Enforcement Actions & $L Q E N=\frac{E N_{S T A T E} / F A C_{S T A T E}}{E N_{U S} / F A C_{U S}}$ \\
\hline LQENAVG & Enforcement actions & Four-year average of LQEN prior to LQIN \\
\hline LQTRI & $\begin{array}{l}\text { Per capita TRI releases (only the original } \\
\text { core chemicals) }\end{array}$ & $L Q T R I=\frac{\text { TRI }_{\text {STATE }} / \text { POP }_{\text {STATE }}}{\text { TRI }_{\text {US }} / \text { POP }_{U S}}$ \\
\hline LQELEC & $\begin{array}{l}\% \text { of voting population by state for } \\
\text { presidential elections 1988, } 1992 \text { and } 1996\end{array}$ & $L Q E L E C=\frac{V_{O T E_{S T A T E}} / P_{P O P_{S T A T E}}}{V_{\text {OTE }} / P_{U S}}$ \\
\hline LQCIT & $\begin{array}{l}\text { Ratio of a state's "citizen political ideology" } \\
\text { score to the US average (Berry, Ringquist, } \\
\text { Fording, and Hansen, 1998) }\end{array}$ & LQCIT $=\frac{\text { CITSCORE }_{\text {STATE }}}{\text { CITSCORE }_{\text {US(avg.) }}}$ \\
\hline LQGOV & $\begin{array}{l}\text { Ratio of a state’s “elected public official } \\
\text { political ideology" score to the US average } \\
\text { (Berry, Ringquist, Fording, and Hansen, } \\
\text { 1998) }\end{array}$ & $L Q G O V=\frac{G O V S C O R E_{S T A T E}}{\text { GOVSCORE }}$ \\
\hline LQDENSITY & population per square mile by state & LQDENSITY $=\frac{P_{\text {OPTATE }} / \text { AREA }}{P_{\text {STATE }}}$ \\
\hline LQGSP & real 1996 gross state product per capita & $L Q G S P=\frac{G S P_{S T A T E} / P_{\text {POP }} \text { STATE }}{G D P_{U S} / P_{U S}}$ \\
\hline LQGSP26 & $\begin{array}{l}\% \text { GSP in SIC } 26 \text { (pulp and paper) of total } \\
\text { manufacturing GSP }\end{array}$ & 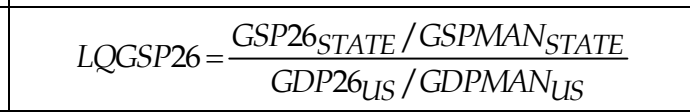 \\
\hline LQGSP28 & $\begin{array}{l}\% \text { GSP in SIC } 28 \text { (chemicals) of total } \\
\text { manufacturing GSP }\end{array}$ & 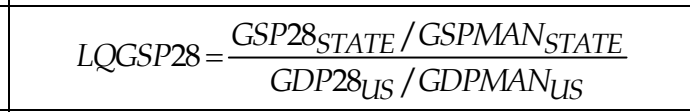 \\
\hline LQGSP29 & $\begin{array}{l}\text { \% GSP in SIC } 29 \text { (petroleum refining) of } \\
\text { total manufacturing GSP }\end{array}$ & LQGSP29 $=\frac{\text { GSP29 }_{\text {STATE }} / \text { GSPMAN }_{\text {STATE }}}{\text { GDP29 }_{\text {US }} / \text { GDPMAN }_{\text {US }}}$ \\
\hline LQGSP30 & $\begin{array}{l}\text { \% GSP in SIC } 30 \text { (rubber and plastics) of } \\
\text { total manufacturing GSP }\end{array}$ & LQGSP30 $=\frac{\text { GSP30 }_{\text {STATE }} / \text { GSPMAN }_{\text {STATE }}}{\text { GDP30 US }_{\text {US }} / \text { GDPAN }_{\text {US }}}$ \\
\hline LQGSP33 & $\begin{array}{l}\text { \% GSP in SIC } 33 \text { (iron and steel) of total } \\
\text { manufacturing GSP }\end{array}$ & LQGSP33 $=\frac{\text { GSP33 }_{\text {STATE }} / \text { GSPMAN }}{\text { STATE }}$ \\
\hline LQTRI26 & $\begin{array}{l}\% \text { TRI PER UNIT GSP in SIC } 26 \text { (pulp and } \\
\text { paper) of total TRI PER UNIT GSP }\end{array}$ & 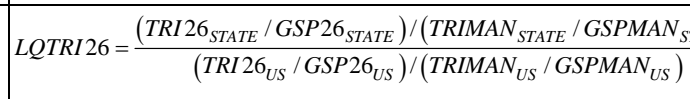 \\
\hline LQTRI28 & $\begin{array}{l}\% \text { TRI PER UNIT GSP in SIC } 28 \\
\text { (chemicals) of total TRI PER UNIT GSP }\end{array}$ & 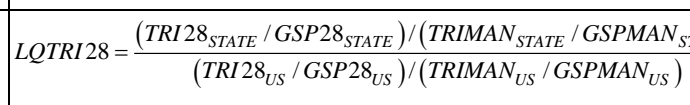 \\
\hline LQTRI29 & $\begin{array}{l}\begin{array}{l}\% \text { TRI PER UNIT GSP in SIC } 29 \\
\text { (petroleum refining) of total TRI PER UNIT } \\
\text { GSP }\end{array} \\
\end{array}$ & 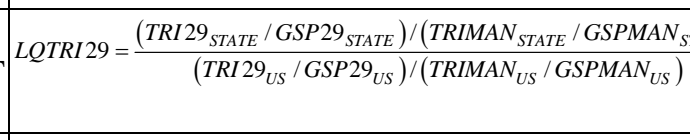 \\
\hline LQTRI30 & $\begin{array}{l}\text { \% TRI PER UNIT GSP in SIC } 30 \text { (rubber } \\
\text { and plastics) of total TRI PER UNIT GSP }\end{array}$ & 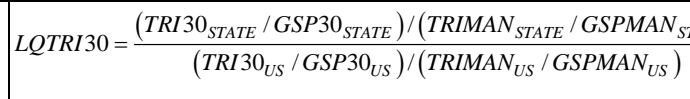 \\
\hline LQTRI33 & $\begin{array}{l}\text { \% TRI PER UNIT GSP in SIC } 33 \text { (iron and } \\
\text { steel) of total TRI PER UNIT GSP }\end{array}$ & 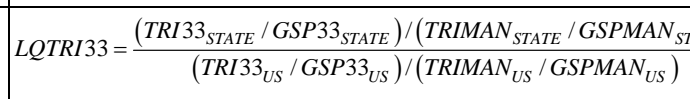 \\
\hline
\end{tabular}


